Check for updates

Cite this: RSC Adv., 2019, 9, 37403

Received 26th July 2019

Accepted 2nd October 2019

DOI: $10.1039 / c 9 r a 05810 a$

rsc.li/rsc-advances

\section{Removal of chromium(vi) from polluted wastewater by chemical modification of silica gel with 4-acetyl- 3-hydroxyaniline}

\begin{abstract}
Ali Bilgiç (iD) * and Aysel Çimen
In the current study, a new adsorbent that is insoluble in water and many acid solutions and has a high adsorption capacity for $\mathrm{Cr}(\mathrm{vI})$ metal ions was synthesized. In the synthesis process, 3-chloropropyltrimethoxysilane (CPTS) was first modified on a silica gel (Si) surface. Secondly, 4-acetyl-3-hydroxyaniline (AHAP) was immobilized on the modified silica gel compound (Si-CPTS). As a result of the immobilization process, a new adsorbent compound named Si-CPTS-AHAP (silica gel-3chloropropyltrimethoxy silane 4-acetyl-3-hydroxyaniline) was obtained, which was used to separate $\mathrm{Cr}(\mathrm{VI})$ ions from aqueous solution $\left(\mathrm{K}_{2} \mathrm{Cr}_{2} \mathrm{O}_{7}\right)$ and industrial wastewater. The material was characterized using scanning electron microscopy and Fourier-transform infrared spectroscopy. The amount of chromium adsorbed was detected by ultraviolet-visible spectroscopy. The adsorption was evaluated using batch methods. The effects of temperature, $\mathrm{pH}$, concentration, adsorbent amount and interaction time on the adsorption of Si-CPTS-AHAP were also investigated. The adsorption of $\mathrm{Cr}(\mathrm{VI})$ ions on SiCPTS-AHAP was investigated via adsorption kinetics, isotherm and thermodynamic studies. The value of the isotherm parameters and the highest adsorption yields were calculated from the DubininRadushkevich, Freundlich and Langmuir isotherm equations. Thermodynamic features such as entropy $(\Delta S)$, enthalpy $(\Delta H)$ and free energy $(\Delta G)$ were also calculated from the experimental results. The experimental results showed that the best recoveries of $\mathrm{Cr}(\mathrm{VI})$ metal ions are under the conditions of $180 \mathrm{~min}$ (interaction time), $0.05 \mathrm{~g}$ (adsorbent amount) and $323.15 \mathrm{~K}$ (temperature) at $\mathrm{pH} 2$. Si-CPTSAHAP can be used for the removal of poisonous pollutants in wastewater.
\end{abstract}

\section{Introduction}

The scarcity of clean drinking water in the world has been a problem for decades. Some poisonous organic and inorganic contaminants, especially heavy metal ions such as $\mathrm{Co}(\mathrm{II}), \mathrm{Ni}(\mathrm{II})$, $\mathrm{Cd}(\mathrm{II}), \mathrm{Pb}(\mathrm{II}), \mathrm{Hg}$ (II), $\mathrm{Cr}(\mathrm{III})$ and dyes, enter the food chain via wastewater. As a result, people, animals, and aquatic organisms are adversely affected. ${ }^{\mathbf{1}}$ In humans, toxic metals cause Alzheimer's, Parkinson's, blood pressure problems, stuttering, psychological disorders, hypersensitive reactions, immune system diseases, embolism and amnesia. ${ }^{2}$ These problems can be solved by the removal of domestic wastes and water contaminated from industrial wastes. For a long time, several methods including reverse osmosis, ${ }^{3}$ ion-exchange, ${ }^{4}$ chemical precipitation, ${ }^{5}$ membrane filtration ${ }^{6}$ and adsorption ${ }^{7}$ have been used to remove heavy metal pollution from wastewaters. Among these methods, adsorption is one of the most interesting, because it is high yielding and so is a low-cost method and is used the most widely in the treatment of contaminated water. ${ }^{8}$

Faculty of Kamil Özdağ Science, Department of Chemistry, Karamanoğlu Mehmetbey University, 70200, Turkey. E-mail: alibilgic100@hotmail.com; Fax:+90 33822621 66; Tel: +903382262169
Many kinds of resin such as active carbon, zeolites, silica gel, wood bark, walnut shell, and rice husk have been used as adsorbents in the removal of toxic heavy metal ions from wastewater. ${ }^{9}$

Chromium and its compounds are broadly used in a range of industrial enterprises such as the chemical industry, metallurgy, tanneries, textile dying, wood preserving and metal plating preparation of chromate solution. Hence, chromium pollution has frequently occurred in many industrial zones. Random leaks or insufficient care taken in the storage of waste are the main factors behind chromium contamination..$^{\mathbf{1 0 - 1 4}}$ In nature, chromium compounds are present as $\mathrm{Cr}$ (vI) and $\mathrm{Cr}$ (III) ions. ${ }^{15} \mathrm{Cr}(\mathrm{vI})$ ions are highly soluble as oxyanions, ${ }^{\mathbf{1 6}}$ however, $\mathrm{Cr}(\mathrm{III})$ ions can be easily precipitated as $\mathrm{Cr}(\mathrm{OH})_{3}$ and are less soluble. ${ }^{17} \mathrm{Cr}(\mathrm{vI})$ ions are 1000 times more toxic than $\mathrm{Cr}$ (III) ions. ${ }^{18}$ In contrast, $\mathrm{Cr}(\mathrm{III})$ exhibits lower toxicity in many organisms $^{19}$ and is breathed in through the mouth, but does have carcinogenic properties. ${ }^{15} \mathrm{Cr}(\mathrm{vI})$ ions in wastewater polluted by industrial foundations and other sources cause serious problems and toxic and non-biodegradable substances tend to accumulate in the vital organs of humans. ${ }^{15}$ For this reason, $\mathrm{Cr}(\mathrm{vI})$ ions must be removed from contaminated waters before expulsion into natural bodies of water. 
Silica gel modification has been used in metal ion preconcentration, ${ }^{20}$ exchange, ${ }^{21}$ biotechnology ${ }^{22}$ catalysis ${ }^{23}$ adsorption, ${ }^{24}$ clean technology, and green chemistry ${ }^{25}$ Adsorption is one of the most important methods used in the treatment of heavy metal ions from waste water.

Silica gel (with a micropore size of $6 \mathrm{~nm}$, a surface area of 480$540 \mathrm{~m}^{2} \mathrm{~g}^{-1}$ and low cost) is a good solid support for adsorption because it has chemical, thermal and mechanical stability. ${ }^{26,27} \mathrm{On}$ the surface of silica gel there are two different types of functional groups; siloxane (Si-O-Si) and silanol ( $\mathrm{Si}-\mathrm{OH}){ }^{28,29}$

The silica gel, used as an adsorbent, has the advantages of being robust against organic solvents, thermal stability and is not capable of swelling. The bonding of a substance to the silica gel (Si) surface is easier than bonding to an organic support surface, and the silica gel (Si) is the most popular adsorbent for surface studies. Modified silica gels usually have a higher adsorption capacity than other organic and inorganic supports. Thus, the use of immobilized molecules in the removal of heavy metal ions from industrial wastewater gives better results. ${ }^{30,31}$ In this study, a new surface was formed with the chemical immobilization of suitable organic groups on the silica gel surface. This new silica gel surface can be used as an adsorbent to remove $\operatorname{Cr}(\mathrm{vI})$ heavy metal ions, which show a toxic effect to nature and living things, from industrial wastewater and aqueous solutions.

There are many studies on the removal of $\mathrm{Cr}(\mathrm{vI})$ ions. ${ }^{7,32-34}$ Unlike these studies, we expanded the surface area of silica gel, which is used as a support agent. This was accomplished by modification and immobilization of 3-chloropropyltrimethoxysilane (CPTS) and 4-acetyl-3-hydroxyaniline (AHAP) compounds on silica gel, respectively. The synthesized support material is insoluble in water and many acids due to the properties of the silica gel, does not swell easily due to crosslinking, is cheap and shows reproducibility in experiments. For the first time, the modification of CPTS onto silica gel and the immobilization of AHAP onto Si-CPTS were performed. Using the newly synthesized Si-CPTS-AHAP adsorbent in the removal of $\mathrm{Cr}(\mathrm{vr})$ ions in wastewater treatment systems could potentially provide both low-cost and high-efficiency heavy metal removal. Therefore, the current study has great potential to contribute to the world economy, water and environmental cleanliness. In addition, the adsorption method is cheap, easy to apply and has a short test period.

In this work, the chelating molecule 4-acetyl-3-hydroxyaniline (AHAP) was attached onto a silica gel surface through an immobilization reaction and characterized using Fourier-transform infrared spectroscopy (FTIR) and scanning electron microscope (SEM). This new adsorbent was utilized to remove $\mathrm{Cr}(\mathrm{VI})$ metal ions in industrial wastewater taken from a valve factory in the organized industrial zone in Konya, Turkey. In addition, this new adsorbent was applied to remove aqueous solutions containing trace amounts of $\mathrm{Cr}(\mathrm{vI})$ metal ions.

\section{Materials and methods}

\subsection{Materials}

Silica gel 60 (diameter of $0.063-0.200 \mathrm{~mm}$, micropore size of $6 \mathrm{~nm}$, high surface area of $480-540 \mathrm{~m}^{2} \mathrm{~g}^{-1}$ ), used as the support material of the new adsorbent material, was purchased from Merck (Darmstadt, Germany, www.merck.de). 3-Chloropropyltrimethoxy silane (CPTS), 4-acetyl-3-hydroxyaniline (AHAP) and potassium dichromate $\left(\mathrm{K}_{2} \mathrm{Cr}_{2} \mathrm{O}_{7}\right)$ were purchased from Sigma. Toluene (99.8\%) was purchased from Sigma-Aldrich. A standard $\mathrm{Cr}(\mathrm{vI})$ metal ion solution was freshly prepared daily. Adjustment of the $\mathrm{pH}$ of the industrial wastewater and aqueous solutions was carried out using dilute $\mathrm{NaOH}$ and $\mathrm{HNO}_{3}$ solutions. All the chemicals used in the study were used without further purification unless otherwise stated. Industrial wastewater sample (82.21 $\mathrm{mg} \mathrm{L}^{-1} \mathrm{Cr}(\mathrm{vI}), \mathrm{pH}=2.0$, temperature: $318.15 \mathrm{~K}$, current density: $12-20 \mathrm{~A} \mathrm{dm}^{-2}$ and $\mathrm{H}_{2} \mathrm{SO}_{4}: 8.05 \mathrm{mg} \mathrm{L}^{-1}$ ) containing $\mathrm{Cr}(\mathrm{vI})$ ions was obtained from a valve factory in the organized industrial zone in Konya, Turkey.

\subsection{Instruments}

SEM images of activated silica gel (Si), 3-chloropropyl-bonded silica gel (Si-CPTS) and the Si-CPTS-AHAP adsorbent were obtained using a Zeiss LS-10 device equipped with an Inca Energy 350 X-Max (Oxford Instruments) spectrometer.

FT-IR spectra of the activated silica gel (Si), 3-chloropropyl bonded silica gel (Si-CPTS) and the Si-CPTS-AHAP adsorbent compounds were scanned using a PerkinElmer 100 FTIR spectrometer (ATR; $21{ }^{\circ} \mathrm{C}$ temperature and $1 \mathrm{~atm}$ pressure) in the range of $650-4000 \mathrm{~cm}^{-1}$. The $\mathrm{pH}$ values of $\mathrm{Cr}(\mathrm{vI})$ metal ion solutions were measured using a Jenway 3010 digital pH meter. Amounts of metallic $\mathrm{Cr}(\mathrm{vI})$ cations remaining in solution were determined by ultraviolet-visible (UV) spectroscopy (Optizen brand 3220 model UV-vis).

\subsection{Functionalization of silica gel and immobilization of AHAP}

The preparation of the Si-CPTS-AHAP adsorbent was carried out in three stages. In the first stage, silica gel $(10 \mathrm{~g})$ was refluxed with $6 \mathrm{M}$ hydrochloric acid $(100 \mathrm{~mL})$ for $8 \mathrm{~h}$ to prepare conventional activated silica to remove metal ions and maximize the number of silanol groups on the surface. ${ }^{35,36}$ The resulting suspension was filtered under vacuum and the resulting activated silica gel was washed 3 times with distilled water and twice with ethanol.

In the second stage, the activated silica gel $(5 \mathrm{~g})$ was treated with $5 \mathrm{~mL}$ of 3-chloropropyltrimethoxysilane (CPTS) in $50 \mathrm{~mL}$ of anhydrous toluene ${ }^{37}$ at $96^{\circ} \mathrm{C}$ for $12 \mathrm{~h} .{ }^{38,39}$ The resulting Si-CPTS compound was filtered through the mixture and washed with toluene, ethanol and diethyl ether and dried at $60{ }^{\circ} \mathrm{C}$ for $6 \mathrm{~h}^{38}$ The possible structure of the 3-chloropropyl-bonded silica gel (Si-CPTS) is shown in Fig. 1.

In the third stage, the dried 3-chloropropyl-bonded silica gel (5 g) was mixed with $33 \mathrm{~mL}$ of $25 \%$ 4-acetyl-3-hydroxyaniline (AHAP) solution in $50 \mathrm{~mL}$ of anhydrous toluene $\mathrm{e}^{37}$ and was refluxed under nitrogen for $24 \mathrm{~h}$ at $90{ }^{\circ} \mathrm{C} . .^{38,39}$ The crude product obtained by the filtration of the suspension was washed with water and ether and then dried at $40{ }^{\circ} \mathrm{C}$ for $72 \mathrm{~h}$ under vacuum to afford Si-CPTS-AHAP. ${ }^{28-30}$ The possible structure of the synthesized Si-CPTS-AHAP adsorbent is shown in Fig. 1. 

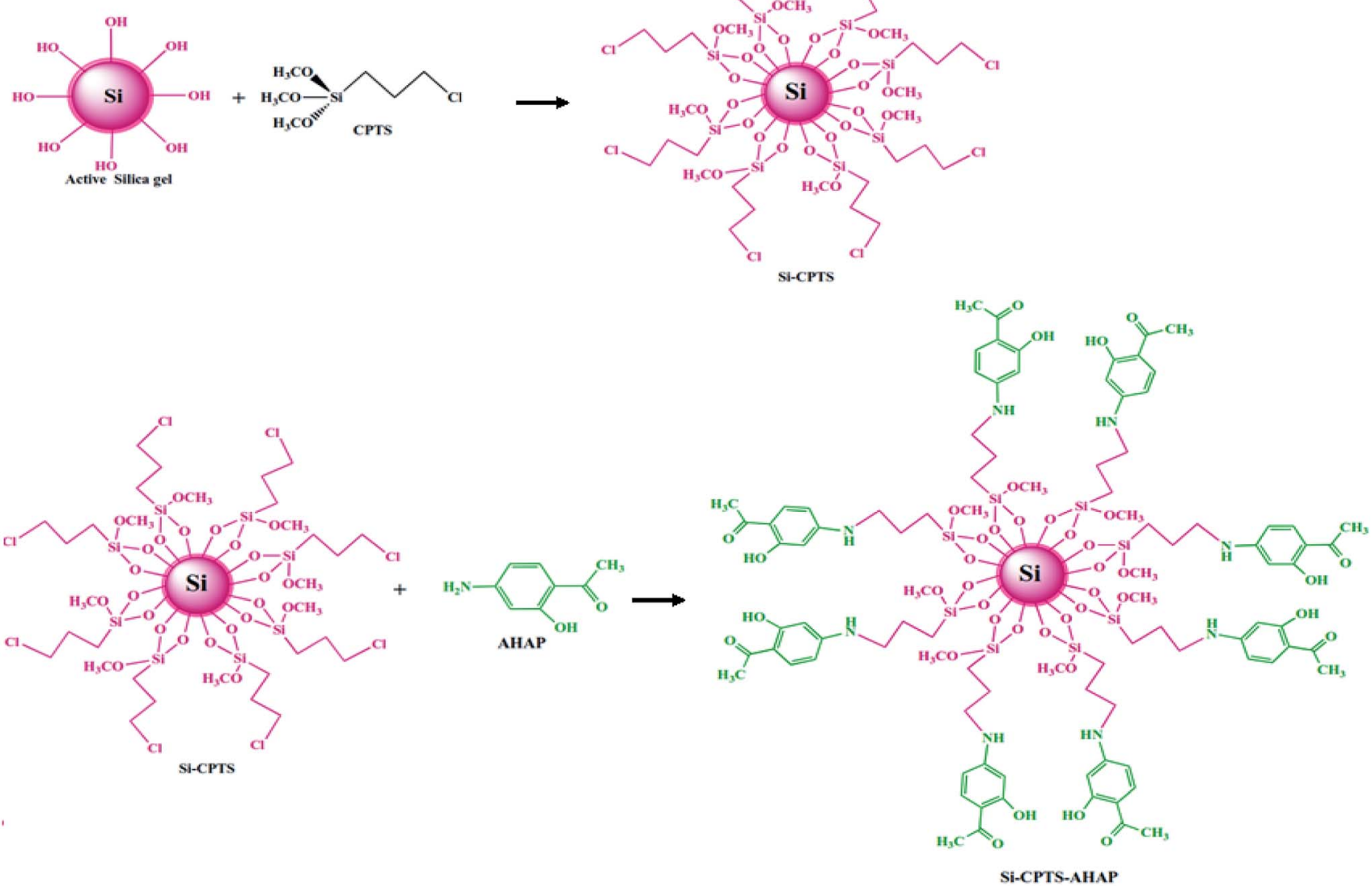

Fig. 1 Possible structure of the synthesized Si-CPTS-AHAP adsorbent.

\subsection{Adsorption studies}

Adsorption experiments were conducted in batch mode, using $20 \mathrm{~mL}$ centrifuge tubes through the contacting of $10 \mathrm{~mL}$ of a 1 $\times 10^{-4} \mathrm{~mol} \mathrm{~L}^{-1}$ metal ion solution and wastewater with $20 \mathrm{mg}$ of Si-CPTS-AHAP adsorbent at $200 \mathrm{rpm}$, for definite time intervals in a temperature controlled shaker incubator.

After the experimental studies and measurements, the amount of $\mathrm{Cr}(\mathrm{vI})$ ions adsorbed onto the Si-CPTS-AHAP adsorbent was calculated using eqn (1):

$$
q_{\mathrm{e}}=\left(C_{0}-C_{\mathrm{e}}\right) \times V / m
$$

where $q_{\mathrm{e}}$ (adsorption capacity) is the amount of adsorbed $\mathrm{Cr}(\mathrm{vI})$ ions at equilibrium $\left(\mathrm{mg} \mathrm{g}^{-1}\right), C_{\mathrm{e}}$ and $C_{0}\left(\mathrm{mg} \mathrm{L}^{-1}\right)$ are the equilibrium and initial concentrations of $\mathrm{Cr}(\mathrm{vI})$ ions in an aqueous solution, $V(\mathrm{~L})$ is the volume of the aqueous chromium solution and $m(\mathrm{~g})$ is the mass of the Si-CPTS-AHAP adsorbent. ${ }^{\mathbf{4 0 , 4 1}}$

\section{5. pH studies}

$\mathrm{pH}$ studies were carried out at various $\mathrm{pH}$ values $(2.0,3.0,4.0$, $5.0,6.0,7.0) .0 .05 \mathrm{~g}$ of the Si-CPTS-AHAP adsorbent at $200 \mathrm{rpm}$ was mixed with a $10 \mathrm{~mL}$ aqueous solution containing $1 \times$ $10^{-4} \mathrm{~mol} \mathrm{~L}^{-1} \mathrm{~K}_{2} \mathrm{Cr}_{2} \mathrm{O}_{7}$ and wastewater. The obtained solutions were shaken for $180 \mathrm{~min}$ at $323.15 \mathrm{~K}^{42}$

\subsection{Concentration studies}

The effect of $\mathrm{Cr}(\mathrm{vI})$ concentration on adsorption was investigated using a batch method for potassium dichromate $\left(\mathrm{K}_{2} \mathrm{Cr}_{2} \mathrm{O}_{7}\right)$ solution and industrial wastewater at $25 \pm 1{ }^{\circ} \mathrm{C}$. For these adsorption measurements, $0.05 \mathrm{~g}$ of the Si-CPTS-AHAP adsorbent was suspended in $10 \mathrm{~mL}$ of aqueous solution containing different amounts of potassium dichromate $\left(\mathrm{K}_{2} \mathrm{Cr}_{2} \mathrm{O}_{7}\right)$ solution and industrial wastewater. These suspensions were shaken in various $\mathrm{Cr}(\mathrm{vI})$ concentrations $\left(8,12,20,40 \mathrm{mg} \mathrm{L}^{-1}\right)$ in a shaker thermostat for $180 \mathrm{~min}$ at $323.15 \mathrm{~K} .{ }^{43}$ After adsorption equilibrium was established, the amounts of $\mathrm{Cr}(\mathrm{vI})$ metal ion residues in solution were detected by ultraviolet-visible (UV) spectroscopy.

\subsection{Temperature studies}

$0.05 \mathrm{~g}$ of the Si-CPTS-AHAP adsorbent and $10 \mathrm{~mL}$ of a $0.0001 \mathrm{~mol} \mathrm{~L}^{-1} \mathrm{Cr}(\mathrm{vI})$ metal ion solution at an optimum $\mathrm{pH}$ of 2.0 were added into a series of conical flasks. All flasks containing the Si-CPTS-AHAP adsorbent and $\mathrm{Cr}(\mathrm{vI})$ metal solution were kept in a water bath equipped with a thermostat.

All suspensions in the flasks were stirred for $150 \mathrm{~min}$ at $(20 \pm$ $0.01),(30 \pm 0.01),(40 \pm 0.01)$ and $(55 \pm 0.01){ }^{\circ} \mathrm{C}$, respectively. The amounts of the adsorbed $\operatorname{Cr}(\mathrm{vI})$ metal ion residues in 
solution were detected by UV spectroscopy and calculated from the change in $\mathrm{Cr}(\mathrm{vI})$ metal concentrations in aqueous solution.

\subsection{Contact time studies}

In this study, the solution concentration, $\mathrm{pH}$ value and temperature parameters were kept constant, $0.05 \mathrm{~g}$ of the SiCPTS-AHAP adsorbent against $10 \mathrm{~mL}$ of $1 \times 10^{-4} \mathrm{~mol} \mathrm{~L}^{-1}$ stock $\mathrm{Cr}(\mathrm{vI})$ metal solutions were activated separately at different (30, 60, 90, 120, 150 and 180 minutes) contact times. In addition, this method was applied to an industrial waste solution. The amount of adsorbed $\mathrm{Cr}(\mathrm{vI})$ metal ion residues in solution was detected by UV spectroscopy and the maximum contact time was determined from the obtained data.

\subsection{Studies of the effect of the adsorbent quantity on adsorption}

In order to investigate the effect of the amount of adsorbent, the relationship between the amount of $\mathrm{Cr}(\mathrm{vI})$ metal ions adsorbed on the adsorbent surface using different adsorbent amounts (0.01, 0.015, 0.025, 0.05 and $0.075 \mathrm{~g}$ ) was investigated.

\subsection{Adsorption isotherm models}

Adsorption equilibrium is an essential feature in adsorption studies. Considering this, numerous investigations were conducted to determine the amount of metal ions adsorbed under certain conditions. To optimize the design of an adsorption system to remove heavy metal ions from aqueous solutions, it is important to find the most appropriate correlation for the balance curve. ${ }^{47}$ Adsorption isotherms are the most appropriate way to evaluate the adsorption process. In this study, Langmuir, Freundlich and Dubinin-Radushkevich (D-R) adsorption isotherm models were used to process the experimental equilibrium data to verify which model gives the best fit. Adsorption isotherms can be investigated by changing the initial concentrations of pollutant chromium, keeping the other process parameters constant in terms of $\mathrm{pH}$, temperature, processing time and agitation speed. ${ }^{48}$ In this study, the models used in Table 1 are shown with mathematical expressions.

\subsection{Adsorption thermodynamics}

In the adsorption studies, thermodynamic parameters such as free energy change $(\Delta G)$, entropy change $(\Delta S)$ and enthalpy change $(\Delta H)$ are very important. These parameters provide information about how the adsorption process takes place. The effect of temperature on the adsorption of the newly synthesized Si-CPTS-AHAP adsorbent was investigated at temperatures between 20 and $50{ }^{\circ} \mathrm{C}$ under optimized conditions of $\mathrm{pH}$, contact time and concentration values, for each of the $\mathrm{Cr}(\mathrm{vI})$ ion solutions. The values of the thermodynamic parameters, including the Gibbs free energy $(\Delta G)$, enthalpy $(\Delta H)$ and entropy $(\Delta S)$ were calculated from the following equations: $:^{49,50}$

$$
\Delta G=-R T \ln K_{\mathrm{c}}
$$

where $R$ is the universal gas constant $\left(8.314 \mathrm{~J} \mathrm{~mol}^{-1} \mathrm{~K}^{-1}\right)$ and $K_{\mathrm{c}}$ is the ratio between the $C_{\mathrm{e}}$ adsorbent and $C_{\mathrm{e}}$ solution

$$
\begin{gathered}
\Delta G=\Delta H-T \Delta S \\
\ln K_{\mathrm{c}}=\Delta S / R-\Delta H^{\circ} / R T
\end{gathered}
$$

\section{Results and discussion}

\subsection{Characterization}

3.1.1. FT-IR analysis. The FT-IR spectra of the activated

\begin{tabular}{|c|c|c|c|c|}
\hline Model & Linear equation & Plot & Nomenclature & Ref. \\
\hline Langmuir & $\frac{C_{\mathrm{e}}}{q_{\mathrm{e}}}=\frac{C_{\mathrm{e}}}{q_{\mathrm{o}}}+\frac{1}{q_{\mathrm{o}} K_{\mathrm{L}}}$ & $C_{\mathrm{e}} / q_{\mathrm{e}} v s . C_{\mathrm{e}}$ & $\begin{array}{l}q_{\mathrm{o}} \text { is the maximum surface density at } \\
\text { monolayer coverage, } C_{\mathrm{e}} \text { is the } \\
\text { equilibrium ion concentration in the } \\
\text { solution, } q_{\mathrm{e}} \text { is the amount of solute } \\
\text { adsorbed on the surface of the adsorbent, } \\
K_{\mathrm{L}} \text { is the energy constant for Langmuir }\end{array}$ & 44 \\
\hline Freundlich & $\ln q_{\mathrm{e}}=\ln K_{\mathrm{F}}+\frac{\ln C_{\mathrm{e}}}{n}$ & $\ln q_{\mathrm{e}} v s . \ln C_{\mathrm{e}}$ & $\begin{array}{l}q_{\mathrm{e}} \text { is the equilibrium solute } \\
\text { concentration on the adsorbent, } n \text { is } \\
\text { a constant reflecting the adsorption } \\
\text { intensity, } C_{\mathrm{e}} \text { is the equilibrium solute } \\
\text { concentration on the adsorbent, } K_{\mathrm{F}} \text { is the } \\
\text { Freundlich constant }\end{array}$ & 45 \\
\hline $\begin{array}{l}\text { Dubinin-Radushkevich } \\
\text { (D-R) }\end{array}$ & $\begin{array}{l}\ln q_{\mathrm{e}}=q_{\mathrm{m}}-k \varepsilon^{2} \\
E=(2 k)^{-1 / 2}\end{array}$ & $\ln q_{\mathrm{e}} v s . \varepsilon^{2}$ & $\begin{array}{l}q_{\mathrm{e}} \text { is the amount of solute adsorbed per } \\
\text { unit weight of adsorbent, } \varepsilon \text { (Polanyi } \\
\text { potential) is }[R T \ln (1+(1 / C))], q_{\mathrm{m}} \text { is the } \\
\text { adsorption capacity }\left(\mathrm{mol}^{-1}\right), k \text { is } \\
\text { a constant related to the adsorption } \\
\text { energy, } E \text { is the value of the mean free } \\
\text { energy }\end{array}$ & 46 \\
\hline
\end{tabular}
silica gel (Si), 3-chloropropyl bonded silica gel (Si-CPTS) and Si-

Table 1 Mathematical expressions used in the adsorption isotherm models 
CPTS-AHAP adsorbent were recorded by a PerkinElmer 100 spectrometer using the potassium bromide $(\mathrm{KBr})$ disc method and are shown in Fig. 2.

The FT-IR spectrum of the activated silica gel shows a band at $1058 \mathrm{~cm}^{-1}$ due to the asymmetric stretching of Si-O-Si and corresponding symmetric stretching was observed at $795 \mathrm{~cm}^{-1} .^{51}$ The characteristic peaks of the $\mathrm{Si}-\mathrm{O}-\mathrm{H}$ groups of the activated silica gel were observed at $967 \mathrm{~cm}^{-1}$ (ref. 52) and also strong and broad peaks at around $3465 \mathrm{~cm}^{-1}$ can be attributed to the hydroxyl group $(\mathrm{O}-\mathrm{H})$ stretching vibrations. ${ }^{53}$ The peak observed at $1637 \mathrm{~cm}^{-1}$ demonstrates the presence of physically adsorbed water in the silica gel samples. ${ }^{54}$

In the FTIR spectrum of Si-CPTS, C-H peaks ${ }^{51}$ were observed at approximately $2977 \mathrm{~cm}^{-1}$ and $\mathrm{C}-\mathrm{Cl}$ peaks ${ }^{55,56}$ were observed at around $684 \mathrm{~cm}^{-1}$. The $\mathrm{OH}$ peak observed for active $\mathrm{Si}$ at $3465 \mathrm{~cm}^{-1}$ shifted to 3487 from $3465 \mathrm{~cm}^{-1}$ in the Si-CPTS compound. The $\mathrm{OH}$ peak also shifted from 3487 to $3485 \mathrm{~cm}^{-1}$ for the Si-CPTS-AHAP. ${ }^{54}$

For the Si-CPTS compound, the observed Si-O-Si tensile vibration was $1049 \mathrm{~cm}^{-1}$, whereas in the Si-CPTS-AHAP adsorbent this stretching vibration was observed to be $1039 \mathrm{~cm}^{-1}$. $\mathrm{C}-\mathrm{H}$ asymmetric and symmetrical stretching vibrations were seen in the range of $2923-2860 \mathrm{~cm}^{-1}$ in the spectrum of the SiCPTS-AHAP adsorbent, respectively. ${ }^{55}$

The FT-IR spectrum of Si-CPTS-AHAP shows the presence of a $\mathrm{C}=\mathrm{C}$ peak at $1431 \mathrm{~cm}^{-1}$ and the appearance of a new band at $1479 \mathrm{~cm}^{-1}$, both characteristic of the vibrations of the $\mathrm{C}=\mathrm{C}$ bonds of aromatic rings and also exhibits new peaks such as $\mathrm{C}-\mathrm{N}$ at $1204 \mathrm{~cm}^{-1}$ and $\mathrm{C}-\mathrm{O}-\mathrm{H}$ at $1150 \mathrm{~cm}^{-1}$. These indicate that AHAP is fixed to the surface of the silica gel.
3.1.2. Elemental composition analysis. Elemental composition analyses of the activated silica gel $\left(\mathrm{SiO}_{2}\right)$, 3-chloropropylbonded silica gel (Si-CPTS) and Si-CPTS-AHA were carried out to determine the percentages of nitrogen (N), carbon (C) and hydrogen $(\mathrm{H})$ in the samples, ${ }^{57}$ the results of which are shown in Table 2.

Percentages of $34.25,2.31$ and $5.04 \%$ for carbon (C), hydrogen $(\mathrm{H})$ and nitrogen $(\mathrm{N})$, respectively, confirmed the surface modification of silica with AHAP.

3.1.3. SEM images. Adsorption takes place on a surface. Therefore, the speed and degree of adsorption depend on the surface functional groups of the adsorbent, the pore size and the surface area. SEM is one of the most widely used surface identification methods, ${ }^{58}$ therefore; SEM micrographs were acquired (by applying a $50 \mathrm{kV}$ electron acceleration voltage) to observe the surface morphologies of the activated silica gel ( $\mathrm{Si}$ ) and Si-CPTS-AHAP adsorbent. An SEM micrograph of activated silica gel (Si) is shown in Fig. 3(a). As can be seen from Fig. 3(a),

Table 2 Percentages (\%) of nitrogen (N), carbon (C) and hydrogen (H) in the activated silica gel (Si), 3-chloropropyl-bonded silica gel (SiCPTS) and Si-CPTS-AHAP adsorbent

\begin{tabular}{llll}
\hline Surface & Nitrogen $(\%)$ & Carbon $(\%)$ & Hydrogen $(\%)$ \\
\hline $\mathrm{SiO}_{2}$ & 0 & 0 & 0 \\
$\mathrm{Si}-\mathrm{CPTS}$ & 0 & 7.22 & 0.82 \\
Si-CPTS-AHAP & 5.04 & 34.25 & 2.31
\end{tabular}

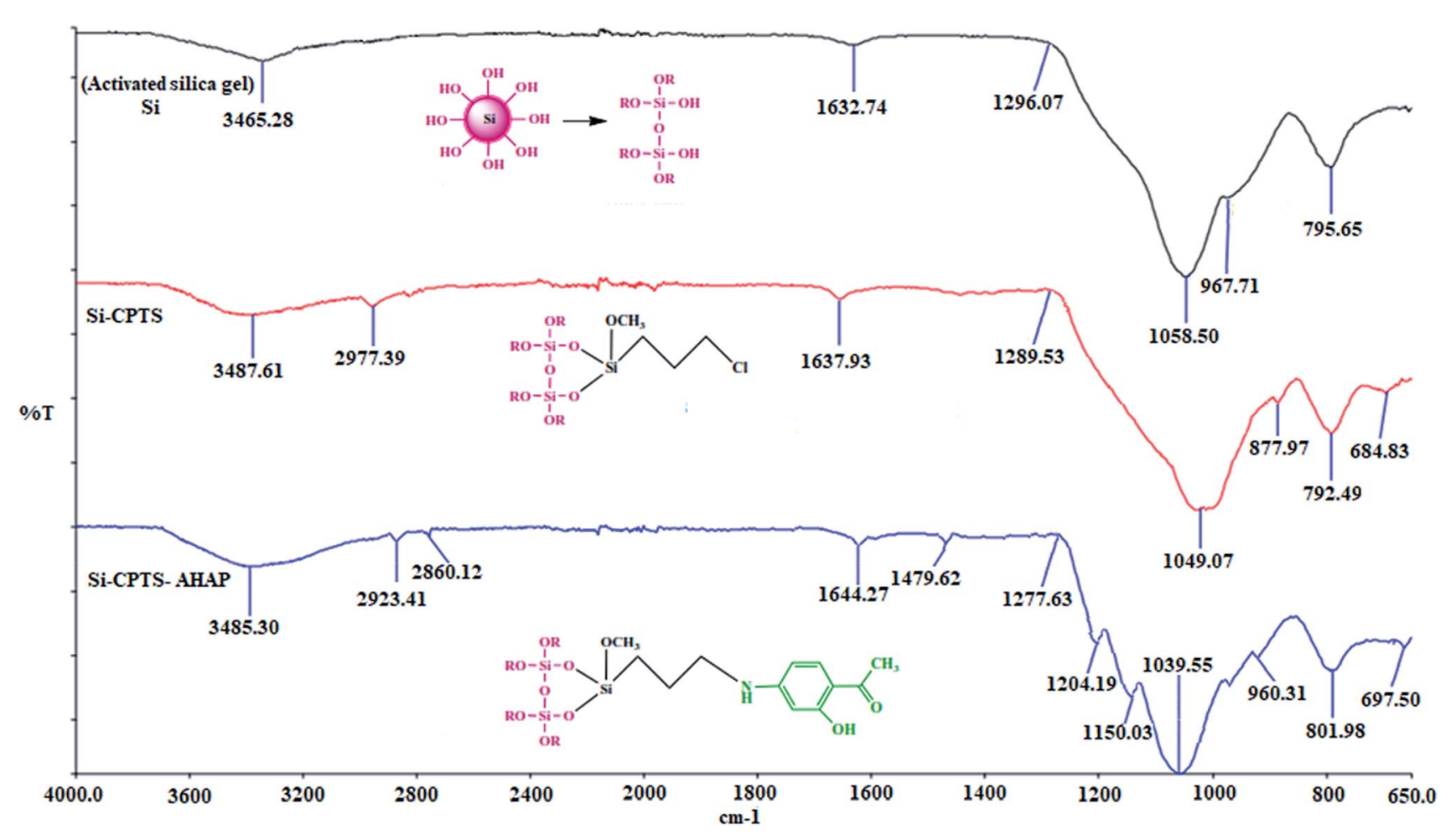

Fig. 2 FTIR spectra of the activated silica gel (Si), 3-chloropropyl-bonded silica gel (Si-CPTS) and the Si-CPTS-AHAP adsorbent. 
the active silica gel surface has a very smooth morphology. An SEM micrograph of the Si-CPTS adsorbent is shown in Fig. 3(b), which exhibits an irregular morphology covered by CPTS. The structure of the active Si surface changed. However, no clear change was observed as much as the change observed in the SiCPTS-AHAP adsorbent, as shown in Fig. 3(c). The SEM micrograph of the Si-CPTS-AHAP adsorbent obtained after the immobilization of AHAP on the active silica gel surface is shown in Fig. 3(c). It shows an irregular morphology covered by impurities, i.e. AHAP and CPTS. The presence of attached particles of AHAP and CPTS onto the surface of the activated silica gel verified the immobilization.
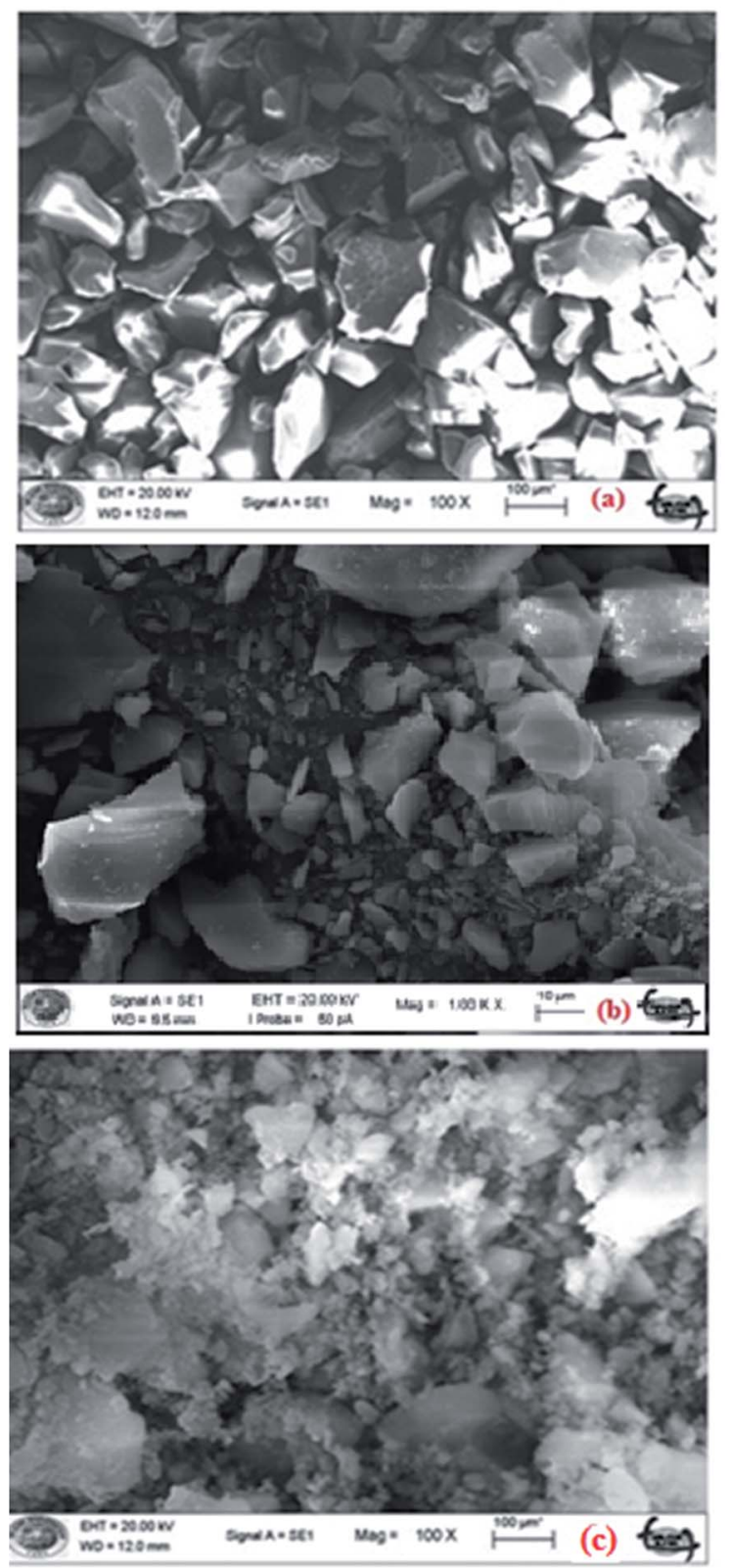

Fig. 3 SEM images of the (a) activated silica gel (Si), (b) Si-CPTS adsorbent and (c) Si-CPTS-AHAP adsorbent.

\subsection{Adsorption studies}

3.2.1. Effect of $\mathbf{p H}$ on adsorption. It is well-known that $\mathrm{pH}$ is one of the most significant factors that effects the adsorption process. ${ }^{59}$ The effects of $\mathrm{pH}$ on the adsorption of chromium ions in aqueous solution and wastewater were investigated between pH 2.0 and 7.0 using Si-CPTS-AHAP as the adsorbent. Experiments were not carried out under extreme alkaline conditions, as at higher $\mathrm{pH}$ values precipitation of chromium hydroxide occurs. Potassium dichromate $\left(\mathrm{K}_{2} \mathrm{Cr}_{2} \mathrm{O}_{7}\right)$ was used to prepare a standard solution of $\mathrm{Cr}(\mathrm{vI})$. In acid solutions, $\mathrm{Cr}(\mathrm{vI})$ becomes negatively charged $\left(\mathrm{HCrO}_{4}{ }^{-}\right.$and $\left.\mathrm{Cr}_{2} \mathrm{O}_{7}{ }^{2-}\right)$. A graphical representation of the effect of $\mathrm{pH}$ is shown in Fig. 4(a). As seen in Fig. 4(a), the adsorption capability of the Si-CPTS-AHAP adsorbent decreases with increasing $\mathrm{pH}$. Experimental results show that the adsorption of $\mathrm{Cr}(\mathrm{vI})$ ions in aqueous solution and wastewater is reduced at high $\mathrm{pH}^{60}$ The adsorption of $\mathrm{Cr}(\mathrm{vI})$ ions in aqueous solution and wastewater reached a maximum in $\mathrm{pH} 2 .^{61}$

It can be seen that the adsorption mechanism of $\mathrm{Cr}(\mathrm{vI})$ ions on the adsorbent (Si-CPTS-AHAP) is based on chelation and the donor nitrogens and $\mathrm{OH}$ groups are coordinated to the chemisorbed heavy metal ions on the surface. It is possible to say that $\mathrm{HCr}_{2} \mathrm{O}_{7}{ }^{-}$and $\mathrm{Cr}_{2} \mathrm{O}_{7}{ }^{2-}$ anions are electrostatically attracted by the acetophenone (positive charge effect) groups on the Si-

(a)

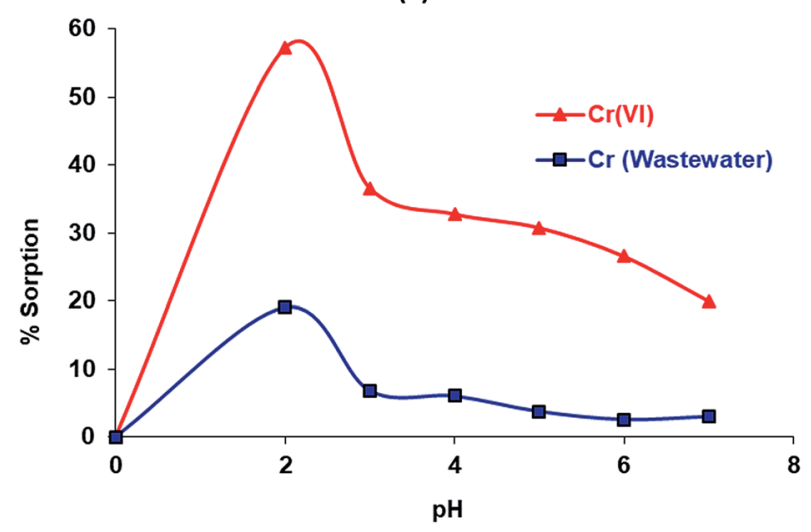

(b)

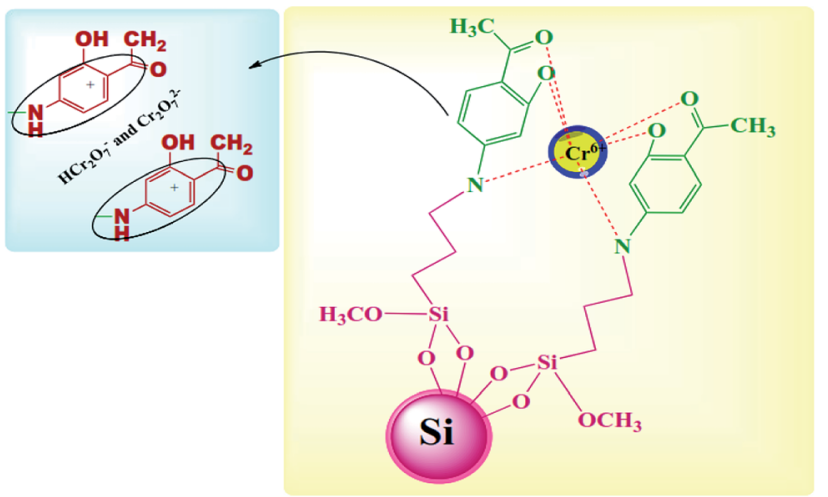

Fig. 4 (a) The effect of $\mathrm{pH}$ on the sorption of $\mathrm{Cr}(\mathrm{Vl})$ in aqueous solution and wastewater. (b) Si-CPTS-AHAP Cr(vI) metal ion combination and a schematic of the electrostatic attraction of acetophenone to $\mathrm{HCl}_{2} \mathrm{O}_{7}^{-}$and $\mathrm{Cr}_{2} \mathrm{O}_{7}{ }^{2-}$ anions. 
CPTS-AHAP adsorbent. A schematic diagram of the Si-CPTSAHAP Cr(vi) metal ion complex is shown in Fig. 4(b). The data obtained were consistent with the literature. ${ }^{48,59,60}$

3.2.2. Effect of concentration on the adsorption. Adsorption takes place on a surface. Therefore, the size of the surface area and the concentration of the substance to be attached to the surface are important. As the surface area of the obtained adsorbent is large, the adsorption percentage increases with the increasing $\mathrm{Cr}(\mathrm{vI})$ ion concentration that is to be adsorbed, as shown in Fig. 5 . As can be seen from the graph, ${ }^{62}$ the adsorption increases with an increase in the concentration of the metal ions. After a while, the adsorption reached steady state values. The data obtained were consistent with the literature. ${ }^{48,61,63}$

3.2.3. Effects of temperature on the adsorption. Temperature is a parameter that affects adsorption. If adsorption occurs endothermically, the temperature increases the amount of adsorption. The situation is reversed for exothermic reactions.

In the experimental study, a batch adsorption method was used to see the influence of varying the temperature $(20-50 \pm$ $0.001{ }^{\circ} \mathrm{C}$ ) on the adsorption of $\mathrm{Cr}(\mathrm{vI})$ ions onto ${ }^{60}$ Si-CPTS-AHAP. The obtained results can be seen in Fig. 6. These results demonstrate that adsorption takes place via an endothermic reaction and increases with temperature. The data obtained were consistent with the literature. ${ }^{48,59-61}$

3.2.4. Effects of contact time on the adsorption. An adsorbent that has hydrophilic groups is defined as the most effective adsorbent. In our study, the reason for the rapid adsorption kinetics may be related to the hydroxy groups in the silica gel and nitrogen of the imine bonds ${ }^{64}$ in the adsorbent $(\mathrm{C}=\mathrm{N})$. The experimental data are shown in Fig. 7. As can be seen from Fig. 7, the Cr(vi) adsorption of the Si-CPTS-AHAP adsorbent shows a very rapid increase with the adsorption time at first $^{62}$ and after a certain contact time, steady state was reached. The data obtained are consistent with the literature. ${ }^{48,59-62}$

3.2.5. Effect of the adsorbent quantity on the adsorption. Several steps were observed (Fig. 8) from the results of experiments on varying the Si-CPTS-AHAP adsorbent quantities $(0.01$, $0.015,0.025,0.05$ and $0.075 \mathrm{~g})$. The study was carried out

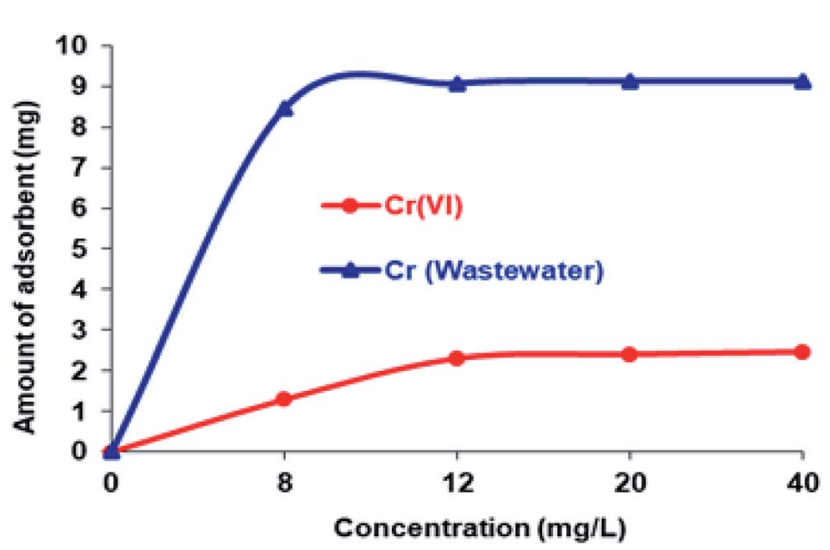

Fig. 5 The adsorption effect depends on the concentrations of $\mathrm{Cr}(\mathrm{VI})$ in aqueous solution and wastewater.

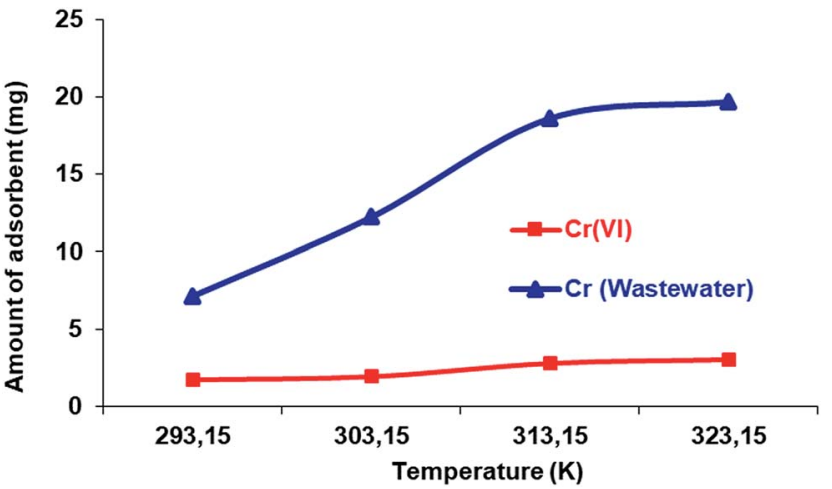

Fig. 6 The effect of temperature on the adsorption of $\mathrm{Cr}(\mathrm{vI})$ from aqueous solution and wastewater.

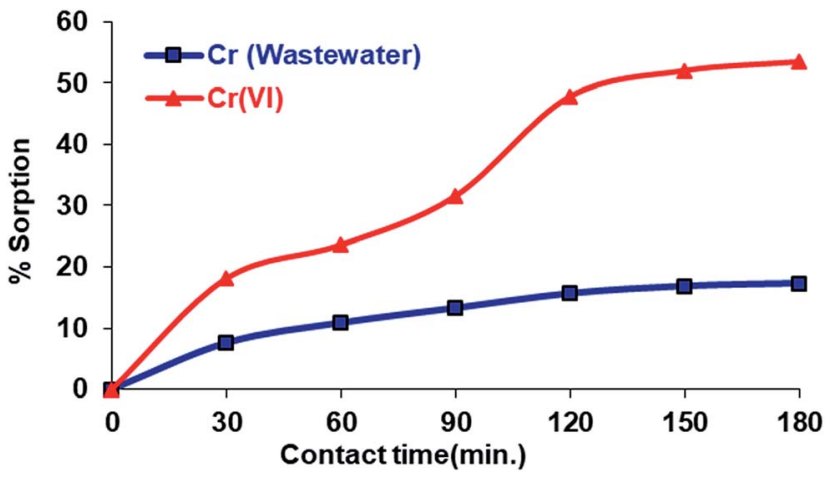

Fig. 7 The effect of the contact time on the adsorption of $\mathrm{Cr}(\mathrm{VI})$ from aqueous solution and wastewater.

separately for $\operatorname{Cr}(\mathrm{vI})$ ions in aqueous solution and industrial wastewater. As can be seen from Fig. 8, the change in the amount of adsorption depends on the increase in the amount of the Si-CPTS-AHAP adsorbent. As shown in Fig. 8, when the amount of Si-CPTS-AHAP adsorbent used was increased, the amount of $\mathrm{Cr}(\mathrm{vI})$ ions adsorbed increased.

As a result, the maximum quantity of the Si-CPTS-AHAP adsorbent needed for adsorbing $\operatorname{Cr}(\mathrm{vI})$ ions from aqueous

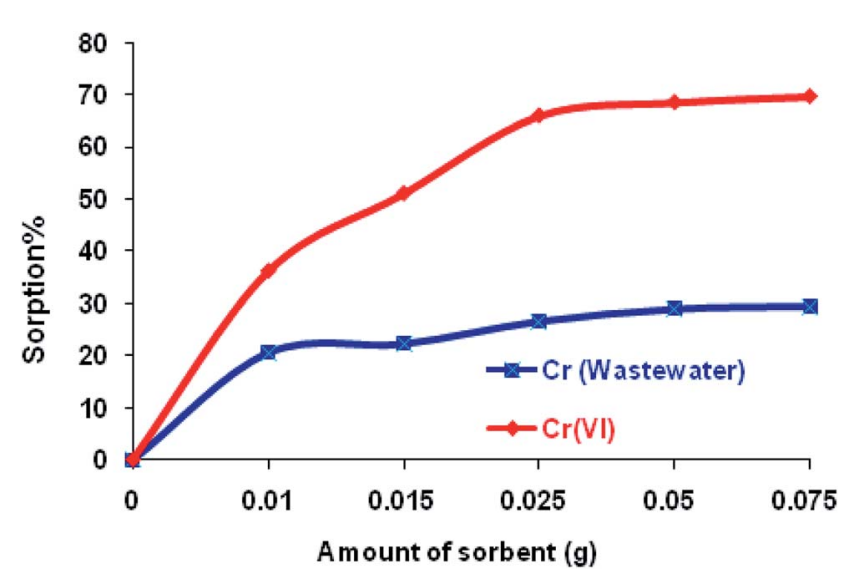

Fig. 8 The effect of the amount of sorbent on the sorption of $\mathrm{Cr}(\mathrm{VI})$ from aqueous solution and wastewater. 
solution and industrial wastewater was found to be $0.05 \mathrm{~g}$. Using $0.05 \mathrm{~g}$ of adsorbent, all active areas on the face of the material were occupied and an increase in the amount of adsorbent did not result in a higher percentage of sorption. The sorption capacity of Si-CPTS-AHAP was found to be $\mathrm{Cr}(\mathrm{vI}): 0.32$ and 3.22 for aqueous solution $\left(\mathrm{K}_{2} \mathrm{Cr}_{2} \mathrm{O}_{7}\right)$ and industrial wastewater, respectively (eqn (1)). ${ }^{65}$ The data obtained were consistent with the literature. ${ }^{48,59-63}$

\subsection{Isotherm studies}

Adsorption isotherms reflect the specific relationship between the adsorbate concentration and degree of deposition on the adsorbent surface at constant temperature. ${ }^{\mathbf{6 6 , 6 7}}$ Equilibrium studies can be carried out to determine the capacity of a adsorbent and define the adsorption isotherm with constants that expressing the values, surface properties and affinity of the adsorbents. ${ }^{68}$ In addition, the adsorption isotherm data was determined using the three most widely used models: the Dubinin-Radushkevich (D-R), Langmuir, and Freundlich models. The parameters obtained from these three models provide important information about the adsorption mechanism and surface properties, the adsorption free energy and the affinity of the adsorbent.

3.3.1. Langmuir adsorption isotherm. Langmuir adsorption isotherms have been successfully applied to many real adsorption processes ${ }^{69}$ and the Langmuir (1918) theory relies on the following assumptions: ${ }^{70}$

- The adsorbate forms a monolayer on the adsorbent surface.

- The active sites are the same.

- The presence of interactions between the molecules that are being absorbed.

- The adsorbent has a limited adsorption capacity $\left(q_{\max }\right)$.

Briefly, the Langmuir adsorption isotherm shows the equilibrium distribution of the metal ions between the solid and liquid phases. ${ }^{65}$ The Langmuir isotherm equation is shown in Table 1. Fig. 9 presents the linear plots of the Langmuir isotherm equation. The values of the parameters in the Langmuir adsorption isotherm equation are summarized in Table 3, as analyzed from the areas shown in Fig. 9.

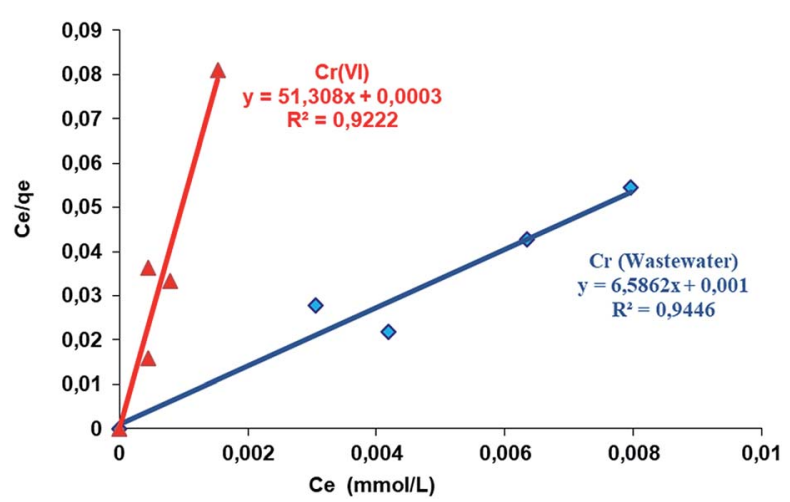

Fig. 9 Langmuir isotherms of the removal of $\mathrm{Cr}(\mathrm{VI})$ from aqueous solution and wastewater by Si-CPTS-AHAP.
Table 3 Parameters of the Langmuir isotherms for $\mathrm{Cr}(\mathrm{VI})$ adsorption onto the Si-CPTS-AHAP adsorbent

Parameters of the Langmuir isotherms

\begin{tabular}{llllll}
\hline Metal & $\mathrm{pH}$ & $T(\mathrm{~K})$ & $q_{\mathrm{o}}(\mathrm{L} \mathrm{mol}$ & $K_{\mathrm{L}}\left(\mathrm{mol}^{2}\left(\mathrm{~kJ}^{2}\right)^{-1}\right)$ & $R^{2}$ \\
\hline Cr(vI) & 2 & 323.15 & 0.174 & 92.800 & 0.922 \\
Cr (wastewater) & 2 & 323.15 & 0.060 & 144.940 & 0.945 \\
\hline
\end{tabular}

3.3.2. Freundlich adsorption isotherm. The Freundlich adsorption isotherm model is an empirical formula ${ }^{71}$ and is usually applied to multi-layer adsorption systems. The Freundlich adsorption isotherm equation is explained in Table 1. The Freundlich adsorption isotherm equation in Table 1 provides a $\ln q_{\mathrm{e}}-\ln C_{\mathrm{e}}$ graph, a straight line (Fig. 10), and the $K_{\mathrm{F}}$ and $n$ values can be calculated from the intercept and slope of this straight line. ${ }^{72}$ The values of the parameters in the Freundlich adsorption isotherm equation are summarized in Table 4, as analyzed from the areas shown in Fig. 10.

The $1 / n$ values of the Si-CPTS-AHAP adsorbent are shown in Table 3 , where a value of $<1$ is an indication of high adsorption density. ${ }^{73}$ The $K_{\mathrm{F}}$ values as shown in Table 3 show that the newly synthesized Si-CPTS-AHAP adsorbent shows high adsorption of $\mathrm{Cr}(\mathrm{vI})$ metal ions from aqueous solution and industrial wastewater $\left(0.50\right.$ and $\left.0.10 \mathrm{~mol} \mathrm{~L}^{-1}\right){ }^{74}$ Values of $n>1$ are indicative of suitable adsorption conditions. ${ }^{75}$

3.3.3. Dubinin-Radushkevish (D-R) adsorption isotherm. The Dubinin-Radushkevish (D-R) isotherm is useful for

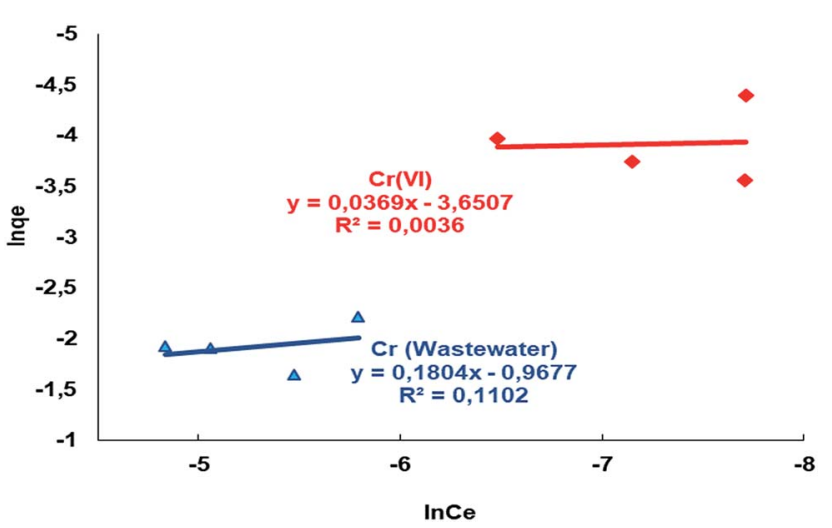

Fig. 10 Freundlich isotherms for the adsorption of $\mathrm{Cr}(\mathrm{VI})$ from aqueous solution and wastewater by the Si-CPTS-AHAP adsorbent.

Table 4 Parameters of the Freundlich isotherms for $\mathrm{Cr}(\mathrm{VI})$ adsorption onto the Si-CPTS-AHAP adsorbent

\begin{tabular}{lccccc}
\hline \multicolumn{7}{l}{ Parameters of the Freundlich isotherms } & & & \\
\hline Metal & $\mathrm{pH}$ & $T(\mathrm{~K})$ & $1 / n$ & $K_{\mathrm{F}}$ & $R^{2}$ \\
\hline $\mathrm{Cr}(\mathrm{vI})$ & 2 & 323.15 & 0.0369 & 0.50 & 0.004 \\
$\mathrm{Cr}($ wastewater) & 2 & 323.15 & 0.1804 & 0.10 & 0.110
\end{tabular}


estimating the characteristic porosity of the adsorbent and deducing the apparent energy of adsorption. ${ }^{76}$ The data was fitted to the $\mathrm{D}-\mathrm{R}$ isotherm model (calculated using the formulae mentioned in Table 1). From the data obtained using the $\mathrm{D}-\mathrm{R}$ adsorption isotherm equation in Table 1 , a graph of $\varepsilon^{2}$ - $\ln q_{\mathrm{e}}$ was plotted (Fig. 11). The $q_{\mathrm{m}}$ value was obtained from the intercept of the graph and the $k$ value was obtained from the slope. ${ }^{77}$

The mean free energy $(E)$ values were calculated using the free energy $(E)$ equation in Table 1, while the mean free energy $(E)$, calculated using the $\mathrm{D}-\mathrm{R}$ adsorption isotherm, is reported in Table 5.

The $E$ values were found to be 50.00 and $20.41 \mathrm{~kJ} \mathrm{~mol}^{-1}$ for $\mathrm{Cr}(\mathrm{vI})$ metal adsorption from aqueous solution and wastewater, respectively, as shown in Table 5. The adsorption of $\mathrm{Cr}(\mathrm{vI})$ from aqueous solution and industrial wastewater took place via chemisorption, where an energy of between 8 and $16 \mathrm{~kJ} \mathrm{~mol}^{-1}$ is sufficient for carrying out the chemical adsorption. ${ }^{78}$ The values of $n$ were $n>1$ at all temperatures, indicated the high affinity of $\mathrm{Cr}(\mathrm{vI})$ ions for the Si-CPTS-AHAP adsorbent.

\subsection{Thermodynamic studies}

The values of the thermodynamic parameters, including the Gibbs free energy $(\Delta G)$, enthalpy $(\Delta H)$ and entropy $(\Delta S)$, were calculated using eqn (6)-(8) and the value of the logarithmic plot of the distribution coefficient $K_{\mathrm{D}}$ against $1 / T$ is shown in Fig. 12. The $\Delta G, \Delta H$ and $\Delta S$ values are presented in Table 6.

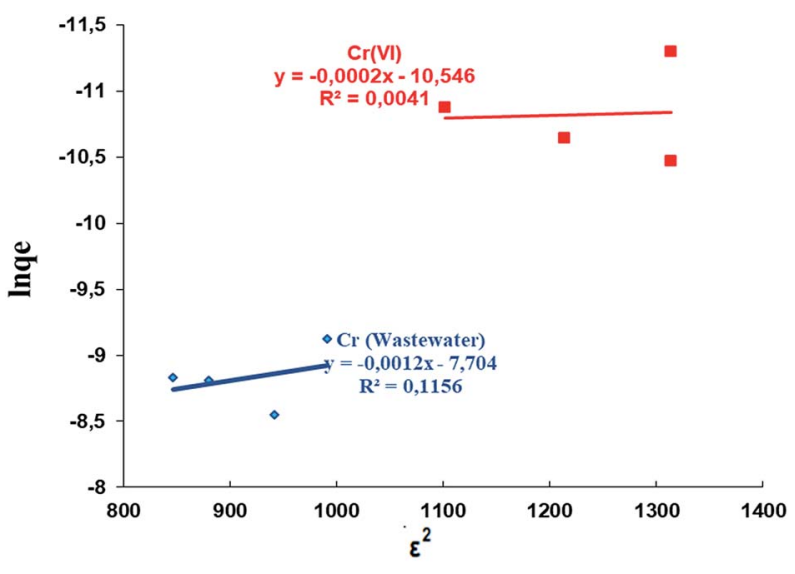

Fig. 11 The D-R isotherms for the adsorption of $\mathrm{Cr}(\mathrm{VI})$ from aqueous solution and wastewater by the Si-CPTS-AHAP adsorbent.

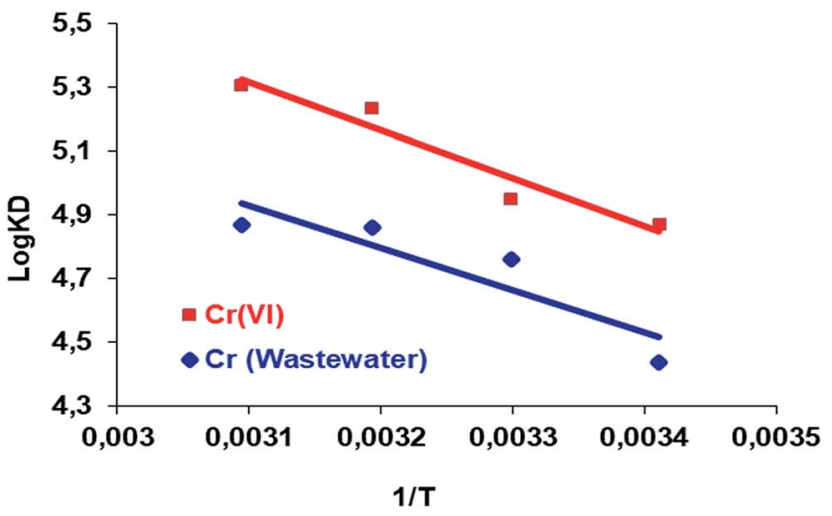

Fig. 12 Plots of $\log K_{\mathrm{D}}$ versus $1 / T$ for the removal of $\mathrm{Cr}(\mathrm{vI})$ from aqueous solution and wastewater by the Si-CPTS-AHAP adsorbent.

As shown in Table 6, the positive presence of the entropy $(\Delta S)$ values indicates that the adsorption reaction is endothermic and the negative values of the Gibbs free energy $(\Delta G)$ indicate that adsorption onto the adsorbent is possible and is a spontaneous process. ${ }^{28}$ The Si-CPTS-AHAP adsorbent has complex forming ability and therefore complex formation must be the predominant mechanism. The positive enthalpy $(\Delta H)$ values also support this notion.

In addition, positive $\Delta S$ values indicate the increased randomness at the solid/liquid interface during the sorption of $\mathrm{Cr}(\mathrm{vI})$ on the selected Si-CPTS-AHAP adsorbent, ${ }^{79}$ which also indicates that ion exchange reactions occur. Metal ions coordinate with the water molecules in solution via covalent bonds and bind to the adsorbent. Due to the release of water molecules, the degree of release increases the magnitude of $\Delta H$ depending on the adsorption energy, indicating the type of binding mechanism, i.e. physical or chemical adsorption. ${ }^{65}$ This process is very rapid and usually reversible due to the small amount of energy required in the physical adsorption. The $\Delta H$ values for $\mathrm{Cr}(\mathrm{vI})$ adsorbed from aqueous solution and wastewater were calculated as 28.75 and $25.59 \mathrm{~kJ} \mathrm{~mol}^{-1}$ in the temperature range of between 20 and $50{ }^{\circ} \mathrm{C}$, respectively. These values are lower than $40 \mathrm{k} \mathrm{J} \mathrm{mol}^{-1}$, indicating the weak interactions of the $\mathrm{Cr}(\mathrm{vI})$ metal ions with the Si-CPTS-AHAP adsorbent surface in the specified temperature range. ${ }^{28,77}$

\subsection{Mechanism}

This adsorption mechanism can be explained by an ion exchange process. However, it is thought that the AHAP functional group undergo a chelating effect with the Si-CPTS-AHAP adsorbent during the adsorption process. It is possible to

Table 5 Parameters of the D-R isotherms for $\mathrm{Cr}(\mathrm{VI})$ adsorption onto the Si-CPTS-AHAP adsorbent

\begin{tabular}{lcccc}
\hline Parameters of the Dubinin-Radushkevish (D-R) isotherms & & \\
\hline Metal & $\mathrm{pH}$ & $T(\mathrm{~K})$ & $k\left(\mathrm{~mol}^{2} \mathrm{~K}^{-1} \mathrm{~J}^{-1}\right)$ & $q_{\mathrm{m}}\left(\mathrm{mol} \mathrm{g}^{-1}\right)$ \\
\hline $\mathrm{Cr}(\mathrm{vI})$ & 2 & 323.15 & 0.0002 & 0.133 \\
$\mathrm{Cr}($ wastewater $)$ & 2 & 323.15 & 0.0012 & 0.061
\end{tabular}


Table 6 Thermodynamic parameters for the sorption of $\mathrm{Cr}(\mathrm{VI})$ from aqueous solution and wastewater by Si-CPTS-AHAP

Thermodynamic parameters

\begin{tabular}{|c|c|c|c|c|c|c|}
\hline \multirow[b]{2}{*}{ Metal } & \multirow[b]{2}{*}{$\Delta H\left(\mathrm{~kJ} \mathrm{~mol}^{-1}\right)$} & \multirow[b]{2}{*}{$\Delta S\left(\mathrm{~J} \mathrm{~K}^{-1} \mathrm{~mol}^{-1}\right)$} & \multicolumn{4}{|c|}{$-\Delta G\left(\mathrm{~kJ} \mathrm{~mol}^{-1}\right)$} \\
\hline & & & $298 \mathrm{~K}$ & $303 \mathrm{~K}$ & $313 \mathrm{~K}$ & $323 \mathrm{~K}$ \\
\hline $\mathrm{Cr}(\mathrm{vI})$ & 28.75 & 142.19 & 12.93 & 13.19 & 12.87 & 13.03 \\
\hline $\mathrm{Cr}$ (wastewater) & 25.59 & 124.15 & 10.81 & 11.99 & 12.65 & 13.07 \\
\hline
\end{tabular}

Table 7 Maximum sorption capacity of different silica-based materials used in the removal of $\mathrm{Cr}(\mathrm{VI})$ ions

\begin{tabular}{|c|c|c|c|}
\hline Adsorbent & $\mathrm{pH}$ & Sorption capacity $\left(\mathrm{mg} \mathrm{g}^{-1}\right)$ & Reference \\
\hline $\mathrm{PANI} / \mathrm{SiO}_{2}$ composite & 4.2 & 63.41 & 81 \\
\hline Cyphos [A336] [C272 functionalized silica (SG-5)] & $0-2$ & 15.29 & 82 \\
\hline Silica & 4 & 1.08 & 83 \\
\hline Silica gel chitosan composite & 4 & 3.5 & 83 \\
\hline La(III) encapsulated silica gel chitosan composite & 4 & 240.0 & 83 \\
\hline Aniline formaldehyde condensate coated on silica gel & 3 & 17.0 & 86 \\
\hline PEI-silica nanoparticles & 4 & 183.7 & 87 \\
\hline Zeolite NaX & 4 & 6.414 & 88 \\
\hline Si-CPTS-AHAP & 2 & 65.0 & Present study \\
\hline
\end{tabular}

interpret that the hydroxyl groups in the Si-CPTS-AHAP adsorbent and the surface coordination of the donor nitrogens are responsible for the chemisorption of $\mathrm{Cr}(\mathrm{vI})$ ions.

The sorption mechanism of $\mathrm{Cr}(\mathrm{vI})$ on Si-CPTS-AHAP can be explained via the binding of oxygens linked to benzene groups. Because $\mathrm{Cr}(\mathrm{vI})$ is a strong hard acid it can easily coordinate with hard bases such as oxygen. Both the carbonyl and oxygen on the benzene groups on Si-CPTS-AHAP, and oxygens which did not react with CPTS on the activated silica gel can be used in the coordination.

\section{Conclusions}

The Si-CPTS-AHAP adsorbent was successfully synthesized and the FT-IR and SEM results confirmed the synthesis of Si-CPTSAHAP adsorbent. Five different parameters were used and based on these results, the best chromium removal was carried out at $\mathrm{pH}=2.0$, with $0.05 \mathrm{~g}$ of adsorbent, at a temperature of $323.15{ }^{\circ} \mathrm{C}$, at a concentration of $20 \mathrm{mg} \mathrm{L}^{-1}$ for a contact time of 180 min. $^{80}$ The Langmuir, Freundlich and D-R adsorption isotherm models were calculated and the adsorption was found to fit to the Langmuir adsorption isotherm model. The mean adsorption energies for immobilized silica gel (Si-CPTS-AHAP) were found to be 50.00 and $20.41 \mathrm{~kJ} \mathrm{~mol}^{-1}$ for $\mathrm{Cr}(\mathrm{vI})$ metal ions from aqueous solution and industrial wastewater, respectively.

Thermodynamic parameters calculated for the adsorption of $\mathrm{Cr}(\mathrm{vI})$ metal ions to the Si-CPTS-AHAP adsorbent surface are endothermic and spontaneous. The values of the free energy change $(\Delta G)$ are negative in the range of $20-50{ }^{\circ} \mathrm{C}$ for spontaneous processes. Free energy change $(\Delta G)$ values decrease as the temperature increases since the adsorption reaction is endothermic. The adsorption of heavy metal ions on the Si-CPTS-AHAP adsorbent is higher at higher temperatures, meaning that it has a high adsorption capacity to remove $\mathrm{Cr}(\mathrm{vI})$ ions from wastewater.

The novelty of this study is the synthesis of the Si-CPTS in our laboratory and the fixing of organic AHAP to the Si-CPTS surface. Since the new material obtained is not soluble in water, this aids in the separation and purification methods and will be helpful for use in other studies.

This work is important in ensuring the effective use of SiCPTS-AHAP in the removal of $\mathrm{Cr}(\mathrm{vI})$ ions in effluent, as well as providing the precise characterization of the synthesized compound. If organizations with heavy metal waste used SiCPTS-AHAP in their waste water treatment systems, they would experience both low-cost and high-efficiency heavy metal removal. Thus, this study contributes to the world economy, water and environmental cleanliness.

The Si-CPTS-AHAP adsorbent was compared with the silicabased adsorbents reported in the literature. Table 7 shows the maximum adsorption capacity and $\mathrm{pH}$ values for the removal of $\mathrm{Cr}(\mathrm{vI})$ ions by Si-CPTS-AHAP compared with various silica-based adsorbents. ${ }^{81}$ It can be seen from the table that the adsorption capacity of Si-CPTS-AHAP in the present study is comparable to the capacity of other adsorbents. ${ }^{81}$

\section{Conflicts of interest}

There are no conflicts to declare. 


\section{Acknowledgements}

The authors thank the Scientific Research Project Commission of Karamanoğlu Mehmetbey University for financial support (BAP-Grant number 11-M-15 and 28-M-15).

\section{References}

1 J. M. Gong, T. Liu, X. Q. Wang, X. L. Hu and L. Z. Zhang, Environ. Sci. Technol., 2011, 45, 6181-6187.

2 M. F. Yardim, T. Budinova, E. Ekinci, N. Petrov, M. Razvigorova and V. Minkova, Chemosphere, 2003, 52, 835-841.

3 B. C. Ricci, C. D. Ferreira, A. O. Aguiar and M. Amaral, Sep. Purif. Technol., 2015, 154, 11-21.

4 G. Sharma, B. Thakur, M. Naushad, H. Ala'a, A. Kumar, M. Sillanpaa and G. T. Mola, Mater. Chem. Phys., 2017, 193, 129-139.

5 F. Fu, L. Xie, B. Tang, Q. Wang and S. Jiang, Chem. Eng. J., 2012, 189-190, 283-287.

6 J. Song, H. Oh, H. Kong and J. Jang, J. Hazard. Mater., 2011, 187, 311-317.

7 M. Naushad, S. Vasudevan, G. Sharma, A. Kumar and Z. ALOthman, Desalin. Water Treat., 2016, 57, 18551-18559.

8 U. Guyo, T. Makawa, M. Moyo, T. Nharingo, B. Nyamunda and T. Mugadza, J. Environ. Chem. Eng., 2015, 3, 2472-2483.

9 H. Kalavathy, I. Regupathi, M. G. Pillai and L. R. Miranda, Colloids Surf., B, 2009, 70, 35-45.

10 R. Shrivastava, R. Upreti and U. Chaturvedi, FEMS Immunol. Med. Microbiol., 2003, 38, 65-70.

11 B. Flury, U. Eggenberger and U. Mäder, J. Appl. Geochem., 2009, 24, 687-696.

12 M. Ragosta, R. Caggiano, M. D'Emilio and M. Macchiato, Atmos. Environ., 2002, 36, 3071-3087.

13 J. A. Zazo, J. S. Paull and P. R. Jaffe, Environ. Pollut., 2008, 156, 29-35.

14 D. E. Kimbrough, Y. Cohen, A. M. Winer, L. Creelman and C. Mabuni, Crit. Rev. Environ. Sci. Technol., 1999, 29, 1-46.

15 S. E. J. G. Fendorf, Geoderma, 1995, 67, 55-71.

16 D. Rai, B. M. Sass and D. A. J. I. C. Moore, Inorg. Chem., 1987, 26, 345-349.

17 A. Pechova and L. Pavlata, Vet. Med., 2007, 52, 1.

18 M. Costa, Toxicol. Appl. Pharmacol., 2003, 188, 1-5.

19 P. d. Magalhães Padilha, L. A. de Melo Gomes, C. C. Federici Padilha, J. C. Moreira and N. L. Dias Filho, Anal. Lett., 1999, 32(9), 1807-1820.

20 J. G. Espinola, S. F. Oliveira, W. E. Lemus, A. G. Souza, C. Airoldi and J. C. Moreira, Colloids Surf., A, 2000, 166, 45-50.

21 K. M. Kallury, W. E. Lee and M. J. A. C. Thompson, Anal. Chem., 1993, 65, 2459-2467.

22 H. E. Fischer, S. A. King, J. B. Miller, J. Y. Ying, J. B. Benziger and J. J. I. C. Schwartz, Inorg. Chem., 1991, 30, 4403-4408.

23 I. C. Ostroski, M. A. S. D. Barros, E. A. Silvab, J. H. Dantas, P. A. Arroyo and O. C. M. Lima, J. Hazard. Mater., 2009, 161, 1404-1412.
24 J. H. Clark and D. J. Macquarrie, Chem. Commun., 1998, 8, 853-860.

25 B. Gao, F. An and K.-K. Liu, Appl. Surf. Sci., 2006, 253, 19461952.

26 O. G. Silva, E. C. S. Filho, M. G. Fonseca, L. N. H. Arakaki and C. Airoldi, J. Colloid Interface Sci., 2007, 301, 376-381.

27 A. G. S. Prado and C. Airoldi, Anal. Chim. Acta, 2001, 432, 201-211.

28 A. Çimen, M. Torun and A. Bilgiç, Desalin. Water Treat., 2015, 53, 2106-2116.

29 Y. Cui, X. Chang, X. Zhu, H. Luo, Z. Hu, X. Zou and Q. He, Microchem. J., 2007, 87, 20-26.

30 İ. H. Gübbük, R. Güp and M. Ersöz, J. Colloid Interface Sci., 2008, 320, 376-382.

31 A. R. Cestari, E. F. S. Vieira, A. J. P. Nascimento, F. J. P. Rodrigues, R. E. Bruns and C. Airoldi, J. Colloid Interface Sci., 2001, 241, 45-51.

32 Z. A. Al-Othman, R. Ali and M. Naushad, Chem. Eng. J., 2012, 184, 238-247.

33 G. Sharma, M. Naushad, H. Ala'a, A. Kumar, M. R. Khan, S. Kalia, M. Bala and A. Sharma, Int. J. Biol. Macromol., 2017, 95, 484-493.

34 S. M. Alshehri, M. Naushad, T. Ahamad, Z. A. Alothman and A. Aldalbahi, Chem. Eng. J., 2014, 254, 181-189.

35 X. Zhu, X. Chang, Y. Cui, X. Zou, D. Yang and Z. Hu, Microchem. J., 2007, 86, 189-194.

36 Y. E. Dolaksiz, F. Temel and M. Tabakci, React. Funct. Polym., 2018, 126, 27-35.

37 S. Schmitz, A. C. Dona, P. Castignolles, R. G. Gilbert and M. Gaborieau, Macromol. Biosci., 2009, 9, 506-514.

38 S. Sivrikaya, M. Imamoglu, S. Z. Yıldız and D. Kara, Anal. Lett., 2016, 49, 943-957.

39 F. Cao, P. Yin, X. Liu, C. Liu and R. Qu, Renewable Energy, 2014, 71, 61-68.

40 S. Guo, H. Xu, F. Zhang, X. Zhu and X. Li, Colloids Surf., A, 2018, 546, 244-253.

41 P. Yin, Q. Xu, R. Qu, G. Zhao and Y. Sun, J. Hazard. Mater., 2010, 173, 710-716.

42 J. A. A. Sales and C. Airoldi, Thermochim. Acta, 2005, 427, 7783.

43 I. H. Gubbuk, J. Hazard. Mater., 2011, 186, 416-422.

44 M. M. Kalhor, A. A. Rafati, L. Rafati and A. A. Rafati, J. Mol. Liq., 2018, 266, 453-459.

45 D. Jiang, Y. Deng, G. Gao, L. Wu and H. Yang, Colloids Surf., A, 2018, 538, 526-533.

46 C. Xiong, S. Wang, W. Sun and Y. Li, Microchem. J., 2019, 146, 270-278.

47 J. S. Piccin, G. L. Dotto and L. A. A. Pinto, Braz. J. Chem. Eng., 2011, 28, 295-304.

48 M. N. Abbas, Eur. Acad. Res., 2014, 2, 8660-8690.

49 A. Q. Selim, E. A. Mohamed, M. Mobarak, A. M. Zayed, M. K. Seliem and S. Komarneni, Microporous Mesoporous Mater., 2018, 260, 84-92.

50 M. Auta and B. H. Hameedd, Chem. Eng. J., 2011, 171, 502509.

51 A. K. Kushwaha, N. Gupta and M. C. Chattopadhyaya, Arabian J. Chem., 2017, 10, S81-S89. 
52 Y. Yang, Q. Li, G. Fang and S. Wang, RSC Adv., 2016, 6, 54510-54517.

53 H.-M. Shen, G.-Y. Zhu, W.-B. Yu, H.-K. Wu, H.-B. Ji, H.-X. Shi, Y.-B. She and Y.-F. Zheng, Appl. Surf. Sci., 2015, 356, 11551167.

54 P. Vejayakumaran, I. A. Rahman, C. S. Sipaut, J. Ismail and C. K. Chee, J. Colloid Interface Sci., 2008, 328, 81-91.

55 F. Adam, H. Osman and K. M. Hello, J. Colloid Interface Sci., 2009, 331, 143-147.

56 J. F. De Conto, M. R. Oliveira, M. M. Oliveira, T. G. Brandão, K. V. Campos, C. C. Santana and S. M. Egues, Chem. Eng. Commun., 2018, 205, 533-537.

57 A. H. Gemeay, E. F. Aboelfetoh and R. G. El-Sharkawy, Water, Air, Soil Pollut., 2018, 229, 16.

58 W. Ngeontae, W. Aeungmaitrepirom and T. Tuntulani, Talanta, 2007, 71, 1075-1082.

59 V. S. O. Ruiz and C. Airoldi, Thermochim. Acta, 2004, 420, 7378.

60 K. Anbalagan, P. S. Kumar and R. Karthikeyan, Desalin. Water Treat., 2016, 57, 12585-12607.

61 G. De la Rosa, J. R. Peralta-Videa and J. L. Gardea-Torresdey, J. Hazard. Mater., 2003, 97, 207-218.

62 R. Coşkun and Y. Dilci, J. Macromol. Sci., Part A: Pure Appl.Chem., 2014, 51, 767-782.

63 T. A. Khan, M. Nazir, I. Ali and A. Kumar, Arabian J. Chem., 2017, 10, S2388-S2398.

64 A. Çimen, A. Bilgiç, A. N. Kursunlu, İ. H. Gübbük and H. İ. Uçan, Desalin. Water Treat., 2014, 52, 4837-4847.

65 A. Çimen, E. Karakuş and A. Bilgiç, Desalin. Water Treat., 2016, 57, 7219-7231.

66 C. S. T. Araújo, I. L. S. Almeida, H. C. Rezende, S. M. L. O. Marcionilio, J. J. L. Léon and T. N. de Matos, Microchem. J., 2018, 137, 348-354.

67 Z. He, J. Yang, H. Li and H. J. E. Song, Environment, Energy and Sustainable Development, 2013, 4, 177.

68 C. Srilakshmi and R. Saraf, Microporous Mesoporous Mater., 2016, 219, 134-144.

69 W. Liu, L. Yang, S. Xu, Y. Chen, B. Liu, Z. Li and C. Jiang, RSC Adv., 2018, 8, 15087-15093.
70 I. Enniya, L. Rghioui and A. Jourani, Sustainable Chem. Pharm., 2018, 7, 9-16.

71 R. Foroutan, H. Esmaeili, M. Abbasi, M. Rezakazemi and M. Mesbah, Environ. Technol., 2018, 39, 2792-2800.

72 B. Hameed, J. Salman and A. L. Ahmad, J. Hazard. Mater., 2009, 163, 121-126.

73 H. A. Akalin, U. Hicsonmez and H. Yllmaz, J. Turk. Chem. Soc., Sect. A, 2018, 5, 85-116.

74 H. Dumrul, A. N. Kursunlu, O. Kocyigit, E. Guler and S. Ertul, Desalination, 2011, 271, 92-99.

75 Y. Wang, X. Tang, Y. Chen, L. Zhan, Z. Li and Q. Tang, J. Hazard. Mater., 2009, 172, 30-37.

76 L. Oubekka, N. Djelali, V. Chaleix and V. Gloaguen, Rev. Roum. Chim., 2016, 61, 175-185.

77 S. A. Chaudhry, T. A. Khan and I. Ali, J. Mol. Liq., 2017, 236, 320-330.

78 R. A. Anayurt, A. Sari and M. Tuzen, J. Chem. Eng., 2009, 151, 255-261.

79 H. Ucun, Y. K. Bayhan and Y. Kaya, J. Hazard. Mater., 2008, 153, 52-59.

80 M. Naushad, T. Ahamad, B. M. Al-Maswari, A. A. Alqadami and S. M. Alshehri, Chem. Eng. J., 2017, 330, 1351-1360.

81 R. Karthik and S. Meenakshi, Journal of Water Process Engineering, 2014, 1, 37-45.

82 Y. Liu, L. Guo, L. Zhu, X. Sun and J. Chen, Chem. Eng. J., 2010, 158, 108-114.

83 M. R. Gandhi and S. Meenakshi, J. Hazard. Mater., 2012, 203, 29-37.

84 J. Y. Qiu, Z. Y. Wang, H. B. Li, L. Xu, J. Peng, M. Zhai, C. Yang, J. Q. Li and G. S. Wei, J. Hazard. Mater., 2009, 166, 270-276.

85 L. Zhao, J. Sun, Y. Zhao, L. Xu and M. Zhai, Chem. Eng. J., 2011, 170, 162-169.

86 P. A. Kumar, M. Ray and S. Chakraborty, J. Hazard. Mater., 2007, 143, 24-32.

87 K. Choi, S. Lee, J. O. Park, J.-A. Park, S.-H. Cho, S. Y. Lee, J. H. Lee and J.-W. Choi, Sci. Rep., 2018, 8, 1438.

88 P. K. Pandey, S. K. Sharma and S. S. Sambi, Int. J. Environ. Sci. Technol., 2010, 7, 395-404. 